\title{
Analysis of Pathfinder SST algorithm for global and regional conditions
}

\author{
Ajoy Kumar, Peter Minnett, Guillermo Podestá \\ RobERT EVANS and KATHERINE KILPATRICK \\ Meteorology and Physical Oceanography Division, Rosenstiel School of Marine and Atmospheric Science, \\ University of Miami, Miami, FL 33149, U.S.A.
}

\begin{abstract}
As part of the Pathfinder program developed jointly by National Aeronautics and Space Administration (NASA) and National Oceanic and Atmospheric Administration (NOAA) a large database of in situ sea surface temperature (SST) measurements coincident with satellite data is now available to the user community. The Pathfinder Matchup Database (PMDB) is a multi-year, multi-satellite collection of coincident measurements from the Advanced Very High Resolution Radiometer (AVHRR) and broadly distributed buoy data (matchups). This database allows the user community to test and validate new SST algorithms to improve the present accuracy of surface temperature measurements from satellites. In this paper we investigate the performance of a global Pathfinder algorithm to specific regional conditions. It is shown that for zenith angles less than $45^{\circ}$, the best-expected statistical discrepancy between satellite and buoy data is about $\sim 0.5 \mathrm{~K}$. In general, the bias of the residuals (satellite - buoy) is negative in most regions, except in the North Atlantic and adjacent seas, where the residuals are always positive. A seasonal signal in SST residuals is observed in all regions and is strongest in the Indian Ocean. The channel-difference term used as a proxy for atmospheric water vapor correction is observed to be unresponsive for columnar water vapor values greater than $45 \mathrm{~mm}$ and high zenith angles. This unresponsiveness of the channels leads to underestimation of sea surface temperature from satellites in these conditions.
\end{abstract}

\section{Introduction}

Satellite derived sea surface temperature (SST) is routinely used for many applications including the study of ocean features and dynamics. The effect of these physical and biological processes on the $\mathrm{CO}_{2}$ air-sea exchange fluxes, carbon cycling in the water column and its burial in sediments is not well understood. One of the goals of the Joint Global Ocean Flux Study (JGOFS) is to understand the global scale oceanic biogeochemical processes and accurate SST measurements stand to enhance this objectivity. Since the accuracy requirement for many applications vary, in general a threshold of $\pm 0.5 \mathrm{~K}$ and an objective of $\pm 0.1 \mathrm{~K}$ in the SST residuals is recommended (Walton et al 1998). A more realistic target of $\pm 0.3 \mathrm{~K}$ (near zero bias) has been identified as that for the Along
Track Scanning Radiometer (ATSR) (e.g. Minnett 1995) and Moderate Resolution Imaging Spectroradiometer (MODIS) SST retrievals (Esaias et al 1998). These values are in turn related to the level of uncertainty required for the use of satellite-derived SSTs in climate research (e.g. Harries et al 1983).

Over the past twenty years, much effort has been invested in developing atmospheric correction algorithms to derive accurate SST from satellite-borne infrared radiometers, particularly the Advanced Very High Resolution Radiometer (AVHRR) that has flown on the TIROS-N/NOAA-series of polar-orbiting satellites since 1978. The Mk2 AVHRR, first flown on the NOAA-7 satellite in 1981 has two channels in the $10-12 \mu \mathrm{m}$ atmospheric transmission "window" that are well suited for the measurement of SST. These are channels 4 and 5 , centered at about $\lambda=10.8$ and

Keywords. Sea surface temperature; AVHRR; satellite; Indian Ocean; matchup. 
$12.0 \mu \mathrm{m}$ and each being about $1.0 \mu \mathrm{m}$ wide. The atmospheric absorption and emission by water vapor, the main clear-air constituent that interacts with the infrared radiation emitted by the sea-surface at these wavelengths, is somewhat greater in channel 5 than in channel 4. This means that the measurement in channel 5 is generally cooler than that in channel 4 , which forms the basis of most atmospheric correction algorithms applied on a pixel-by-pixel basis to derive the SST.

The initial algorithm was a simple linear combination of the channel 4 and 5 brightness temperatures $\left(T_{4}, T_{5}\right)$; the multichannel SST algorithm (MCSST):

$$
\mathrm{SST}=a_{0}+a_{4} T_{4}+a_{5} T_{5}
$$

where $a_{i}$ are the coefficients derived from matchups with buoy data (Strong and McClain 1984) or simulated matchups produced by modeling the atmospheric radiative transfer in the appropriate infrared spectral intervals (Llewellyn-Jones et al 1984). With time, the form of the algorithm has become more complex, with the addition of non-linear terms, resulting in the current operational NLSST (non-linear SST; Walton et al 1998) and the Miami Pathfinder SST (see below, and Kilpatrick et al (2001)).

Regardless of the form of the algorithm, the SST retrieval coefficients are derived by regression analysis of brightness temperatures against in situ SST. The derived SST estimates have zero error and minimized scatter for an ensemble of conditions that match those used to obtain the retrieval coefficients. The retrieval errors can be reduced by having coefficients applicable to specific regions (e.g., Llewellyn-Jones et al 1984) or seasons or other appropriate parameter, such as atmospheric path length (or satellite zenith angle, or scan angle measured from nadir). In an earlier study, Minnett (1990) showed that application of inappropriate coefficients to a regionally or seasonally constrained data set can lead to SST retrieval bias errors up to $1 \mathrm{~K}$. He used simulated data sets derived with a radiative transfer model (see Zavody et al 1995), in a study of SST retrievals in high northern latitudes $\left(>60^{\circ} \mathrm{N}\right)$. The present study extends this using a very large global set of matchups from the Miami Pathfinder data set.

The main objective of this study is to analyze the performance of a global algorithm using the PMDB (Pathfinder Matchup Database). Specifically, we assess the impact of using a global algorithm on regional areas and relate it to other types of data sets, such as water vapor and ship observations.

\section{Data}

The data set we have analyzed consists of sea surface temperature (SST) "observations" obtained from the PMDB. The PMDB is a multi-year, multi-satellite collection of coincident AVHRR and in situ measurements [http://www.rsmas.miami.edu/groups/rrsl/ pathfinder/Matchups/compilation.html]. The in situ data have a broad geographic and temporal distribution, so that algorithm performance can be validated under a wide range of atmospheric and oceanic regimes. The matchups consist of in situ and AVHRR measurements that coincide within \pm 30 minutes and \pm 0.1 degree of latitude and longitude $(\sim 10 \mathrm{~km})$. The in situ observations consist of SST measured from moored and drifting buoys from various sources including National Data Buoy Center (NDBC), Tropical Ocean-Global Atmosphere (TOGA), NOAA Atlantic Oceanographic Marine Laboratory (AOML), etc. The details of the PMDB, Miami Pathfinder algorithm and coefficient estimation are discussed by Kilpatrick et al (2001). Below we summarize some of the main features in the Miami Pathfinder SST calculation. The pathfinder SST algorithm has the form:

$$
\begin{aligned}
\mathrm{SST}_{s}= & a+b T_{4}+c\left(T_{4}-T_{5}\right) \mathrm{SST}_{g} \\
& +d\left(T_{4}-T_{5}\right)(\sec (\theta)-1.0)
\end{aligned}
$$

where $\mathrm{SST}_{s}$ is the satellite-derived SST, $T_{4}, T_{5}$ are the brightness temperatures in AVHRR channels 4 and 5 , $\mathrm{SST}_{g}$ is a first-guess SST, $\theta$, is the satellite zenith angle and $a, b, c$ and $d$ are coefficients derived by regression analysis. The first-guess SST fields in this case are a one-degree interpolated Reynolds SST (Reynolds and Smith 1994). The algorithm coefficients are estimated monthly and separately for dry and wet atmospheres. The monthly coefficients are estimated using matchups from a 5-month, tapered window centered on the month in question. The dry and wet boundary regimes are delineated by the channel difference; $T_{4}-T_{5}=0.7 \mathrm{~K}$. A sequence of tests and filters are used to remove cloud contaminated matchups prior to coefficient estimation (Kilpatrick et al 2001).

We have analyzed a thirteen-year matchup database from 1985-1997 spreading across three different AVHRR sensors (NOAA-9, -11, -14). First, the matchups are filtered to remove clouds and faulty buoy observations and satellite-buoy residual errors that are unreasonably large. Next, in order to provide a stable set of global statistics, the matchups were further constrained to a difference of $\pm 2 \mathrm{~K}$ between the satellite derived and buoy measured SST. After applying the filters, 204082 global matchups were available for the analysis.

The water vapor fields were obtained from the Special Sensor Microwave Imager (SSM/I) product distributed by Remote Sensing Systems (Wentz 1989). For this study, we first made daily half-degree grid maps from the day and night SSM/I quarter-degree daily gridded data. This procedure was adopted so that global daily data availability will be maximized for any given region. Later we extracted data from the daily maps coinciding with satellite and ship observations. 


\section{Algorithm performance}

The Pathfinder algorithm is designed to produce minimum errors in a global set of SST retrievals. The coefficients used in the algorithm, derived by matchups with temperature measurements from buoys, are determined for two water vapor regimes (Kilpatrick et al 2001) and are therefore optimized to the distribution of conditions in the atmosphere and ocean (between the radiating surface of the ocean, i.e. the ocean skin, and the depth of the buoy measurements) represented in the matchups (Minnett 1986; Barton 1995). Systematic errors arise when the algorithm is applied to measurements taken in conditions that do not match those used in the derivation (Eyre 1987; Minnett 1986, 1990). The error characteristics of the SST fields derived by the application of a globally-optimized algorithm in a specific region can be examined by analysis of the matchups in that area; the results indicate relative uncertainties with respect to the performance of the algorithm in the latitudinal zone as a whole.
A comparison of the Pathfinder algorithm performance for different satellite periods is provided in Table 1. This table includes a measure of the scatter of the SST residuals (satellite - buoy) represented by RMSD (root mean square difference), the mean (bias in SST retrievals) and the median. The scatter (rmsd) of the global SST residuals decreases from NOAA-9 to NOAA-14 (0.628 K to 0.536 K). Similar decreases in SST residuals can be observed for various regional areas also. The improvement in the SST errors during NOAA-14 period can be attributed to the better characterization of the AVHRR (Brown et al 1993; Barton 1995). The uncertainties in the SST residuals also depend more on the distribution of the buoys than on the number of buoys as pointed out by Emery et al (1994). The distribution of buoys during NOAA14 period has a wider distribution than that during previous years (figure 1). The wider distribution of buoys account for larger changes in atmospheric conditions and better regression coefficients for SST computation.

Table 1. Summary of SST residuals (satellite - buoy).

\begin{tabular}{|c|c|c|c|c|}
\hline & $\begin{array}{c}\text { NOAA-9 } \\
\text { (Jan. 1985-Nov. 1988) }\end{array}$ & $\begin{array}{c}\text { NOAA-11 } \\
\text { (Nov. 1988-Sep. 1994) }\end{array}$ & $\begin{array}{c}\text { NOAA-9 } \\
\text { (Sep. 1994-Jan. 1995) }\end{array}$ & $\begin{array}{l}\text { NOAA-14 } \\
\text { (Feb. 1995-Dec. 1997) }\end{array}$ \\
\hline Total & 23705 & 84600 & 5864 & 90766 \\
\hline RMSD (K) & 0.628 & 0.603 & 0.519 & 0.536 \\
\hline Median (K) & 0.000 & -0.004 & 0.040 & 0.000 \\
\hline Mean (K) & -0.021 & -0.027 & 0.010 & -0.015 \\
\hline \multirow[t]{4}{*}{ N. Atlantic } & 4113 & 18844 & 1015 & 21178 \\
\hline & 0.608 & 0.596 & 0.544 & 0.534 \\
\hline & 0.160 & 0.070 & 0.050 & 0.053 \\
\hline & 0.180 & 0.047 & 0.040 & 0.0423 \\
\hline \multirow[t]{4}{*}{ S. Atlantic } & 1850 & 2173 & 175 & 3787 \\
\hline & 0.759 & 0.561 & 0.525 & 0.447 \\
\hline & -0.100 & -0.095 & 0.200 & -0.071 \\
\hline & -0.176 & -0.108 & 0.135 & -0.100 \\
\hline \multirow[t]{4}{*}{ N. Pacific } & 10054 & 31876 & 2173 & 29342 \\
\hline & 0.567 & 0.617 & 0.536 & 0.541 \\
\hline & -0.020 & -0.009 & 0.020 & -0.007 \\
\hline & -0.047 & -0.033 & -0.001 & -0.029 \\
\hline \multirow[t]{4}{*}{ S. Pacific } & 3760 & 19609 & 1895 & 17242 \\
\hline & 0.568 & 0.585 & 0.457 & 0.514 \\
\hline & -0.110 & -0.087 & -0.010 & -0.044 \\
\hline & -0.131 & -0.109 & -0.040 & -0.047 \\
\hline \multirow{4}{*}{ Indian } & 1653 & 4590 & 160 & 11775 \\
\hline & 0.832 & 0.628 & 0.539 & 0.553 \\
\hline & -0.110 & -0.016 & 0.060 & -0.075 \\
\hline & -0.132 & -0.048 & 0.022 & -0.108 \\
\hline \multirow[t]{4}{*}{ Mediterranean } & 0 & 1975 & 35 & 3340 \\
\hline & - & 0.597 & 0.943 & 0.549 \\
\hline & - & -0.445 & -0.250 & 0.061 \\
\hline & - & -0.081 & -0.541 & 0.015 \\
\hline \multirow[t]{4}{*}{ Caribbean } & 1919 & 5055 & 391 & 3595 \\
\hline & 0.693 & 0.594 & 0.563 & 0.595 \\
\hline & 0.090 & 0.170 & 0.240 & 0.265 \\
\hline & 0.072 & 0.146 & 0.217 & 0.255 \\
\hline
\end{tabular}




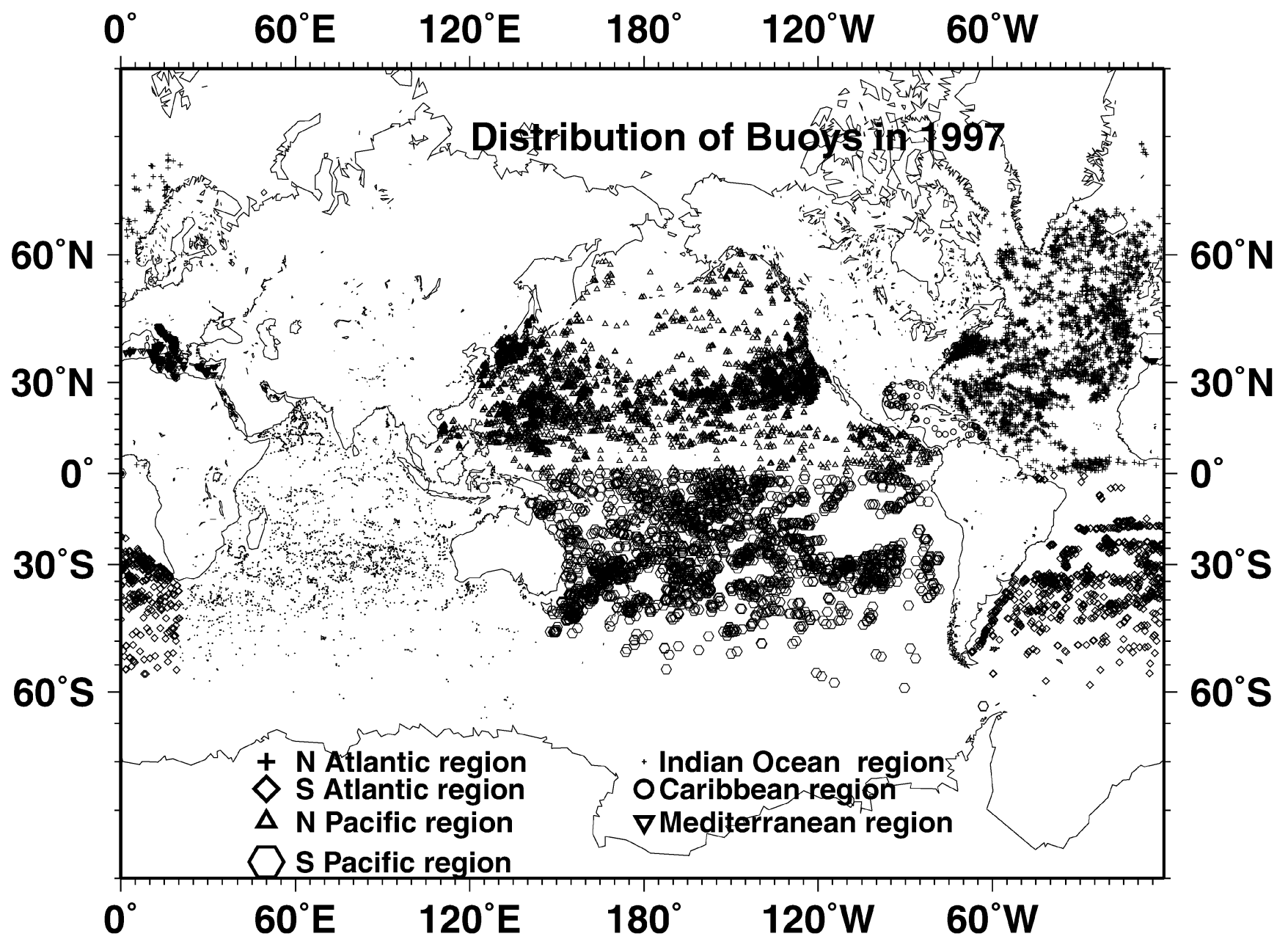

Figure 1. Map of matchup showing the distribution in different regions during 1997.

In general, the mean and median of the Pathfinder SST residuals have a negative bias, i.e. they tend to underestimate the SST when compared with measurements made from buoys. This is consistent with regional variations in the air-sea heat exchanges resulting in a skin effect (e.g, Wick et al 1996) that is different from that in the zone as a whole, or with regional variations the distribution of atmospheric humidity or temperatures when compared to those of the entire zone. The notable exception in this regard is in the N. Atlantic and Caribbean matchups, where the Pathfinder SSTs are consistently overestimated. The Indian Ocean and the S. Atlantic regions show a large negative bias.

Table 2 demonstrates the variations in the performance of a global algorithm to different geographical regions and also at various satellite zenith angles. There are far more matchups in the N Atlantic and the N. and S. Pacific than in the Indian Ocean. The scatter of the regional residuals is between $0.5 \mathrm{~K}$ and $0.6 \mathrm{~K}$ and a global value of $0.575 \mathrm{~K}$ for all zenith angles put together. The Indian Ocean, together with the Caribbean region, shows the largest errors. One of the reasons that may contribute to the larger errors and bias in the Indian Ocean and S. Atlantic regions may be the distribution of the buoys (Shenoi 1999). A larger distribution of matchups from these regions can make greater contribution to the weighting coefficients in the global algorithm. Again, in general the median and the mean are negative with the exception of the N. Atlantic and adjacent seas, the Mediterranean and the Caribbean regions.

An analysis of the matchup database with respect to satellite zenith angle shows better performance of the global algorithm for angles below $45^{\circ}$. The percentages of matchups that fall within different zenith angles are shown in table 2 . The rmsd of the SST residuals fall below $0.5 \mathrm{~K}$ for zenith angles less than $30^{\circ}$ except for the Indian Ocean and the S. Atlantic. The rmsd tends to increase between 30 and $45^{\circ}$. In general, the accuracy of Pathfinder algorithm is $\sim 0.5 \mathrm{~K}$ for zenith angles less than $45^{\circ}$ for the globe and in most regional areas except the Indian Ocean and the Caribbean regions.

Figure 2 shows the distribution of SST residuals with satellite zenith angles for three cases; all 
Table 2. Summary of SST matchups.

\begin{tabular}{|c|c|c|c|c|c|}
\hline & Matchups & $\begin{array}{c}\text { RMSD } \\
\text { Median Mean }\end{array}$ & $\begin{array}{c}\theta<=30^{\circ} \\
\text { RMSD }\end{array}$ & $\begin{array}{c}30^{\circ}<\theta<45^{\circ} \\
\text { RMSD }\end{array}$ & $\begin{array}{c}\theta<=45^{\circ} \\
\text { RMSD }\end{array}$ \\
\hline Total & $\begin{array}{c}204935 \\
(100 \%) \\
-\end{array}$ & $\begin{array}{c}0.575 \\
0.000 \\
-0.020\end{array}$ & $\begin{array}{c}0.490 \\
(34.34 \%)\end{array}$ & $\begin{array}{c}0.525 \\
(22.92 \%)\end{array}$ & $\begin{array}{c}0.504 \\
(57.25 \%)\end{array}$ \\
\hline N. Atlantic & $\begin{array}{c}45150 \\
(22.00 \%)\end{array}$ & $\begin{array}{l}0.568 \\
0.070 \\
0.057\end{array}$ & $\begin{array}{c}0.485 \\
(34.42 \%)\end{array}$ & $\begin{array}{c}0.540 \\
(23.50 \%)\end{array}$ & $\begin{array}{c}0.508 \\
(57.9 \%)\end{array}$ \\
\hline S. Atlantic & $\begin{array}{c}7985 \\
(4.00 \%) \\
-\end{array}$ & $\begin{array}{c}0.566 \\
-0.079 \\
-0.115\end{array}$ & $\begin{array}{c}0.515 \\
(33.00 \%)\end{array}$ & $\begin{array}{c}0.491 \\
(22.84 \%)\end{array}$ & $\begin{array}{c}0.505 \\
(56.25 \%)\end{array}$ \\
\hline N. Pacific & $\begin{array}{c}73445 \\
(35.84 \%) \\
-\end{array}$ & $\begin{array}{c}0.578 \\
-0.010 \\
-0.032\end{array}$ & $\begin{array}{c}0.487 \\
(34.33 \%)\end{array}$ & $\begin{array}{c}0.529 \\
(23.01 \%)\end{array}$ & $\begin{array}{c}0.505 \\
(57.34 \%)\end{array}$ \\
\hline S. Pacific & $\begin{array}{c}42506 \\
(20.74 \%) \\
-\end{array}$ & $\begin{array}{c}0.550 \\
-0.067 \\
0.083\end{array}$ & $\begin{array}{c}0.470 \\
(34.01 \%)\end{array}$ & $\begin{array}{c}0.485 \\
(23.31 \%)\end{array}$ & $\begin{array}{c}0.476 \\
(57.32 \%)\end{array}$ \\
\hline Indian & $\begin{array}{c}18178 \\
(8.87 \%) \\
-\end{array}$ & $\begin{array}{c}0.603 \\
-0.064 \\
-0.094\end{array}$ & $\begin{array}{c}0.527 \\
(33.42 \%)\end{array}$ & $\begin{array}{c}0.536 \\
(21.58 \%)\end{array}$ & $\begin{array}{c}0.530 \\
(55.00 \%)\end{array}$ \\
\hline Mediterranean & $\begin{array}{c}5350 \\
(2.60 \%) \\
-\end{array}$ & $\begin{array}{c}0.570 \\
0.010 \\
-0.046\end{array}$ & $\begin{array}{c}0.481 \\
(33.20 \%)\end{array}$ & $\begin{array}{c}0.537 \\
(21.83 \%)\end{array}$ & $\begin{array}{c}0.504 \\
(55.03 \%)\end{array}$ \\
\hline Caribbean & $\begin{array}{c}10949 \\
(5.34 \%)\end{array}$ & $\begin{array}{l}0.612 \\
0.190 \\
0.171\end{array}$ & $\begin{array}{c}0.500 \\
(37.00 \%)\end{array}$ & $\begin{array}{c}0.571 \\
(21.36 \%)\end{array}$ & $\begin{array}{c}0.525 \\
(58.38 \%)\end{array}$ \\
\hline
\end{tabular}

\section{Plot of SST residuals with satellite angle}

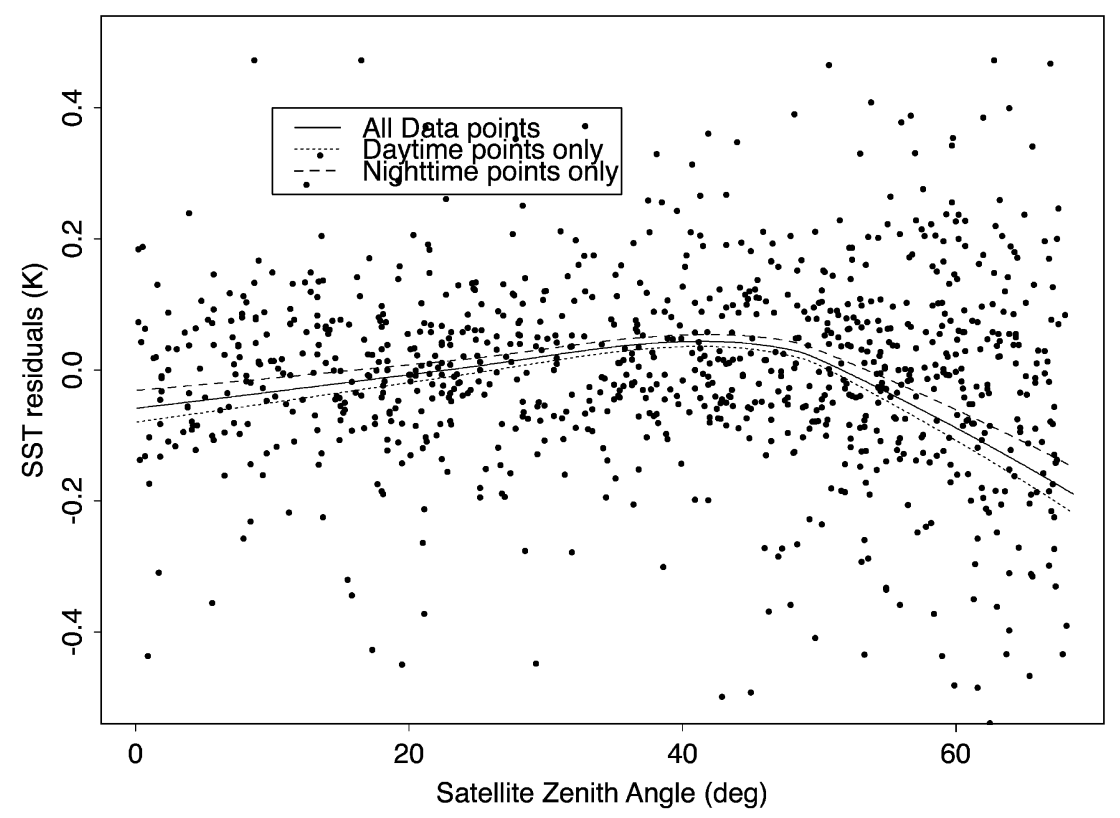

Figure 2. Plot of SST residuals with zenith angles from matchup database (1985 to 1997). A non-parametric trend line (lowess fit) is shown to emphasize the negative residuals for zenith angles greater than $45^{\circ}$. Also shown are trend lines for day and night residuals with zenith angles. They appear to show similar trends. 
data points, daytime only and nighttime only. A scattering smoother function (lowess) is applied to each of the data sets to demonstrate the trend in the data.

About $40 \%$ of the data analyzed have zenith angles greater than $45^{\circ}$. The SST residual trend demonstrates that, for zenith angles larger than $45^{\circ}$, the Pathfinder algorithm appears to underestimate the SST. The underestimation at higher zenith angles is most likely caused by longer path lengths but changes in emissivity are also important at higher latitudes (Minnett 1990). This trend is present for both day and night time data. An analysis of the day matchups gives an rmsd of $0.514 \mathrm{~K}$ and night matchups gives an rmsd of $0.491 \mathrm{~K}$. The marginally worse performance of the daytime matchups may be related to the possible presence of diurnal thermocline effects, which result in a more variable relationship between the skin and bulk temperatures.

\section{Trends in SST residuals}

Temporal trends in global SST residuals can be revealed by means of box plots of the matchup database (figure 3). Each box represents three months of data (January, February and March; April, May and June, etc) during the period 1985 to 1997. The SST residuals show a tighter distribution except during the Mt. Pinatubo eruption period beginning June 1991 and persisting into 1992, when aerosols were injected into the stratosphere causing significant contamination of the AVHRR radiance measurements e.g. (Reynolds 1993). Note the decrease in the size of the whiskers and increase in number of outliers during the later years in the box plots.

Figure 4 shows the regional distribution of SST residuals. Unlike the global plots, there are prominent inter-annual variations in all regions. Seasonal trends also exist, although less apparent because of the

\section{SST residuals (Global)}

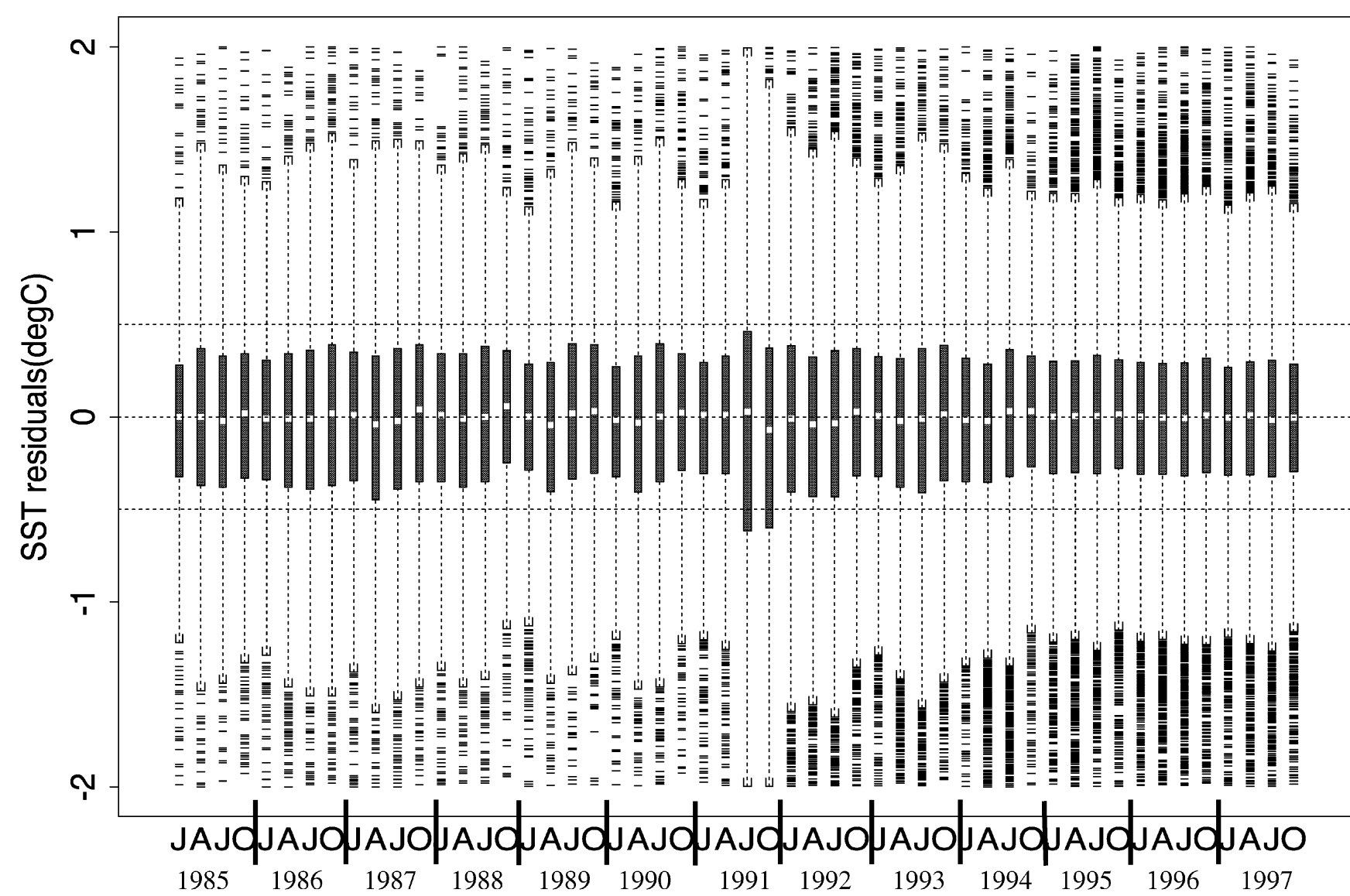

Figure 3. Box plot of SST residuals (Satellite - Buoy data). Each box represents 3 months of data from 1985 to 1997 . For each box plot, the white dot represents the median of SST residuals in a period and the box encompasses the central $50 \%$ of the residuals (i.e. from the 25-percentile to the 75-percentile). The whiskers indicate residuals within 1.5 times the height of the box. Points that lie beyond whiskers are extreme outliers. The dashed line represents, $0, \pm 0.5^{\circ} \mathrm{C}$ residual lines. The characters $\mathrm{J}, \mathrm{A}, \mathrm{J}, \mathrm{O}$ represent each quarter period i.e., beginning with January, April, June and October. The SST residuals shown are limited to $\pm 0.2^{\circ} \mathrm{C} ;$ hence some of the outliers in the plot are truncated. 

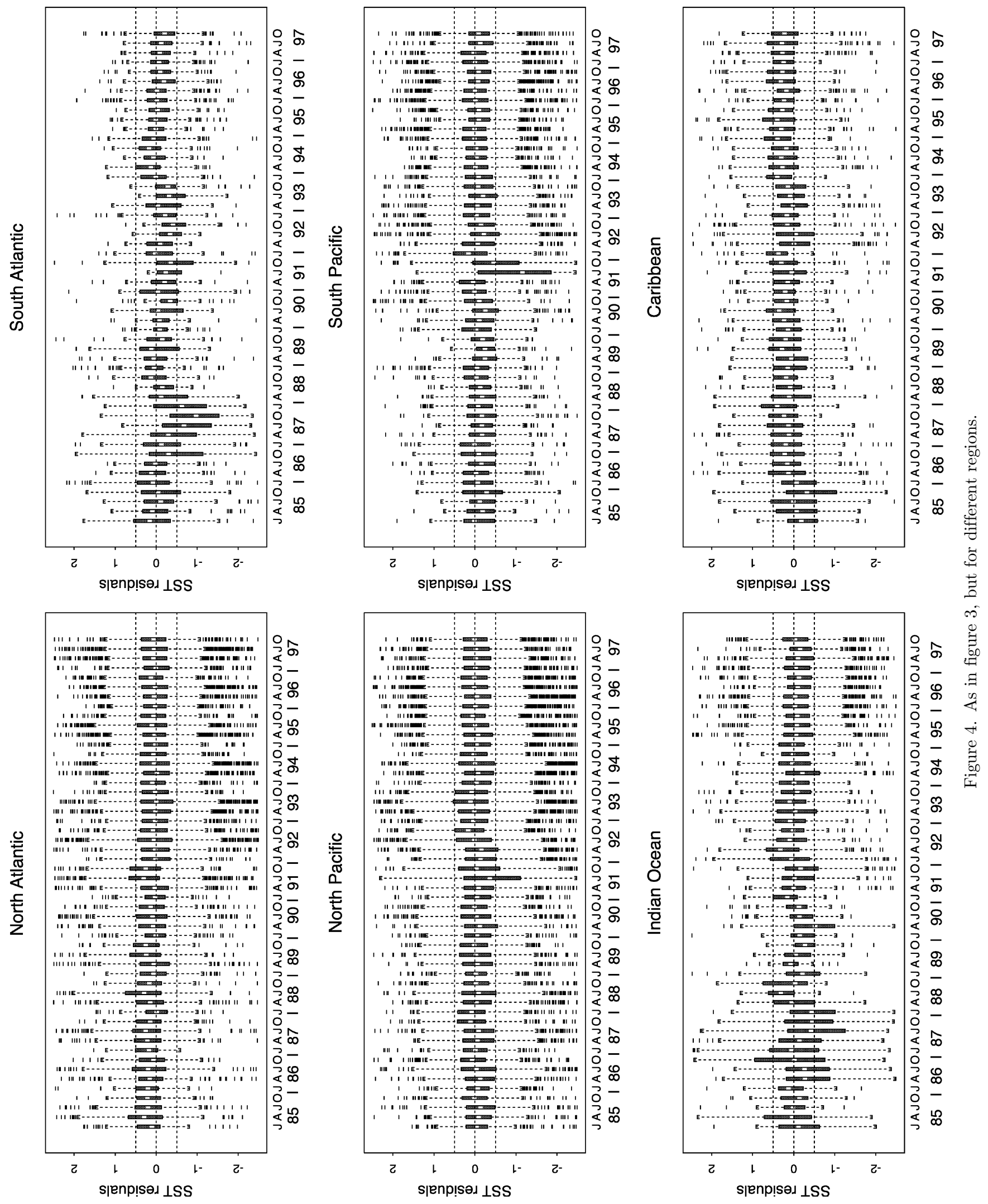
three-month averaging periods of the box plots. These trends suggest that the global Pathfinder algorithm is sensitive to regional atmospheres. As the quality and distribution of buoys in the matchups increase (as in NOAA-14 period), the trend decreases but the number of outliers increases.

A notable feature in these regional plots is that in the N. Atlantic and Caribbean regions, the satellite SST is always warmer than that from the buoys, and inter-annual variations can be observed. In comparison, the N. Pacific residuals tend to be more evenly distributed. In the S. Pacific the SST residuals are on the negative side. In the S. Atlantic the SST error distribution is more erratic, perhaps due to the smaller number of matchups in this area relative to the rest of the globe.

The SST errors in the Indian Ocean area have a slightly different profile. The smaller number of matchups during the early periods may have caused the retrievals to be less robust (Shenoi 1999). But as time progresses, the number of matchups increase and an inter-annual behavior becomes apparent. The seasonal signal is also clearly visible among SST residuals although they are mostly negative.

The main point shown by these plots is that there are prominent inter-annual trends in the regional matchups not apparent in the global distributions. The decrease in trend in NOAA-14 matchups is accompanied by the appearance of extreme outliers, mostly negative. The number of matchups is important in calculating the seasonal trend in certain regions, implying that too small a number of matchups fails to sample adequately the range of environmental variability (Minnett 1986). The satellite SST tends to be underestimated in certain regions and overestimated in others, with the N. Pacific Ocean showing the best behavior of the SST residuals.

\section{Effect of water vapor on SST residuals}

To understand the trend in the SST, especially the outliers in the box plots we have divided the NOAA14 fields from the PMDB randomly into two parts. We then calculated the monthly robust coefficients using the same method as explained in Kilpatrick et al (2001), on one part of the data set and applied these coefficients to the second with-held part and recalculated the SST residuals. We then analyzed these new SST residuals in terms of different parameters. Ideally, the SST residuals should show no dependence on other parameters, but our analysis showed that there are trends with respect to channel brightness temperature differences, zenith angles and SSM/I-derived water vapor fields. The deviation of the trend lines especially at high values of water vapor, channel difference and zenith angles describes the error dependence on these parameters in the global algorithm. To demonstrate this effect, we have shown the deviation as a function of water vapor (figures 5 and 6 ).

We further investigate the dependency of the global algorithm on water vapor and its proxy, $\left(T_{4}-T_{5}\right)$ using matchups for 1996 (figure 5). Figure 6 shows the SST residual and channel difference as a function of $\mathrm{SSM} / \mathrm{I}$ derived water vapor for six different regions. To show the trend in the data a lowess smoothing function is fitted to the channel difference and SST residuals. The SST residuals tend to be underestimated at high water vapor values. The trend line for the channel difference is almost straight with a bend at lower values of SST residuals. This corresponds to the two-level coefficient of the Pathfinder algorithm based on $\left(T_{4}-T_{5}\right)$ differences. But, on further examination of SST residuals for matchups with water vapor values greater than $45 \mathrm{~mm}$, the trend in the channel difference curve appears to level off. This appears to suggest that the channel difference is unresponsive at higher values of water vapor and hence leads to an underestimation of SST in this regime. Changes in the slope of $\left(T_{4}-T_{5}\right)$ with water vapor are consistent with more signal coming from the atmosphere: as the atmosphere becomes moister a larger proportion of radiance from high in the atmospheres (where it is colder) in $T_{5}$ than in $T_{4}$. The SST algorithm is not accounting sufficiently well for less signal originating at sea-surface. In other words, there is a poorer correlation between SST and the temperature of the atmosphere at height. Emery et al (1994) also note this unresponsiveness of channel difference and attribute it to atmospheres at latitudes poleward of $20^{\circ}$. On further analysis, we observe that when the channel difference is higher than a threshold value, it tends to be unresponsive even in dry atmospheres; only in this case it overestimates. Most of the outliers observed in the box plots are characterized by such conditions.

\section{Conclusions}

In this paper we have analyzed the performance of a redefined global algorithm using a time series (thirteen years) of SST residuals from the PMDB. The residuals are the difference between the Miami Pathfinder SST algorithm (Kilpatrick et al 2001) and the SST measured from the buoys. The algorithm performance increases from rsmd uncertainties of $0.628 \mathrm{~K}$ for NOAA-9 to $0.536 \mathrm{~K}$ for the NOAA-14. Our analysis also shows an rmsd of $\sim 0.5 \mathrm{~K}$ for zenith angles less than $45^{\circ}$ for global and most regional areas. Hence, the SST is suitable for many applications as discussed in the introduction. The global algorithm need not perform uniformly all over the globe; one of the concerns is that the global algorithm appears to overestimate the SST in the N. Atlantic and adjoining seas and underestimates elsewhere, especially in the 

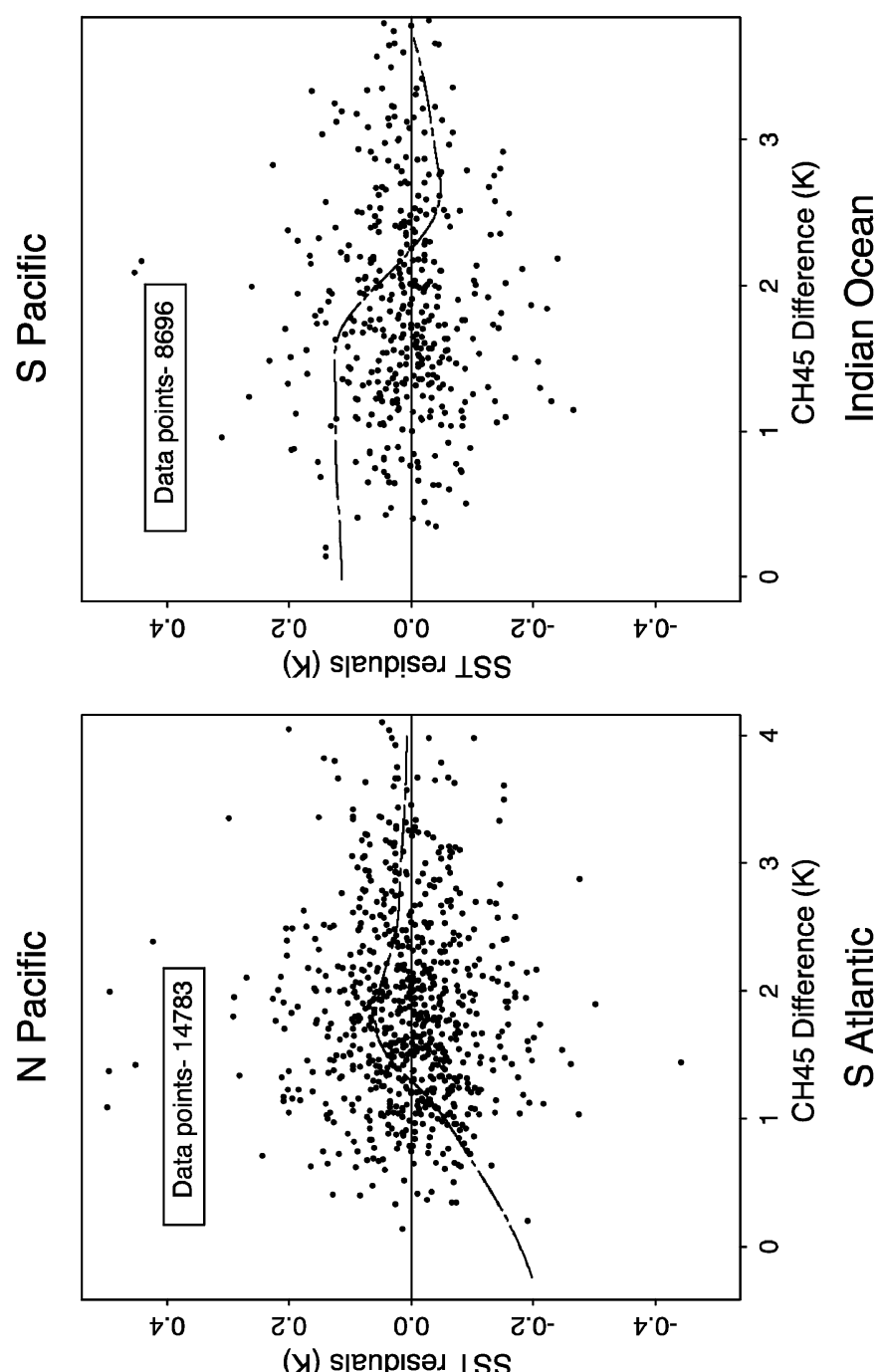

(y) s|enp!sed $\perp S S$
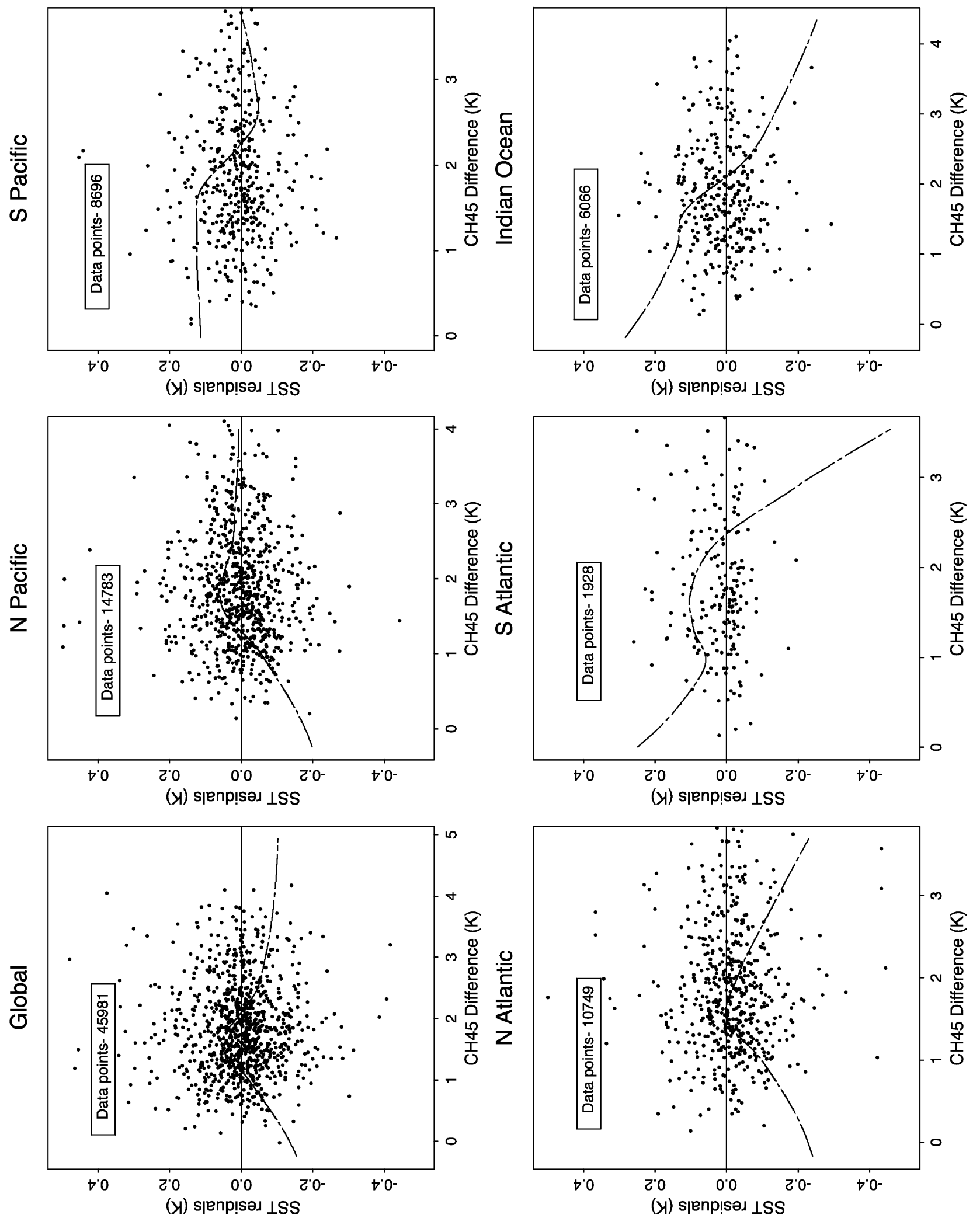

(Y) Sjenp!səd $\perp S S$

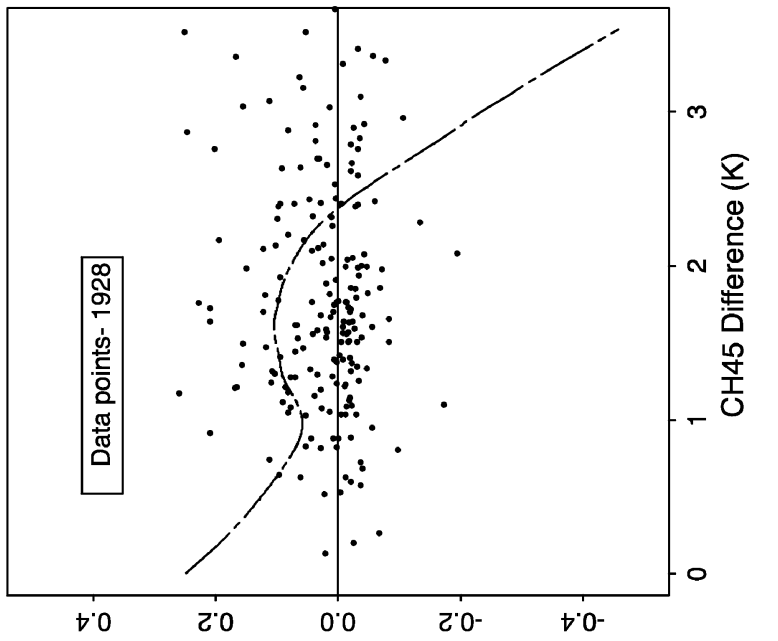

(Y) sjenp!səd $\perp S S$

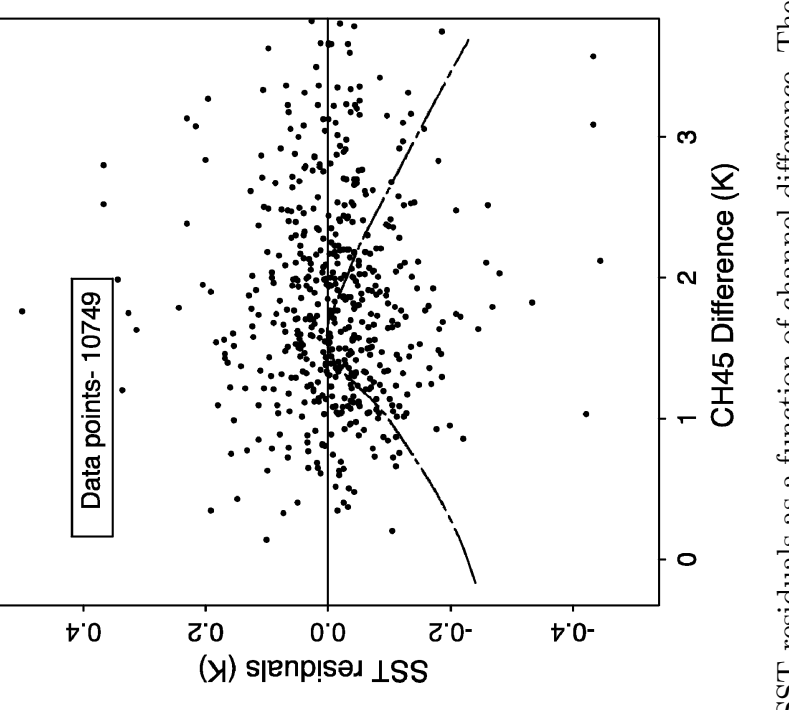




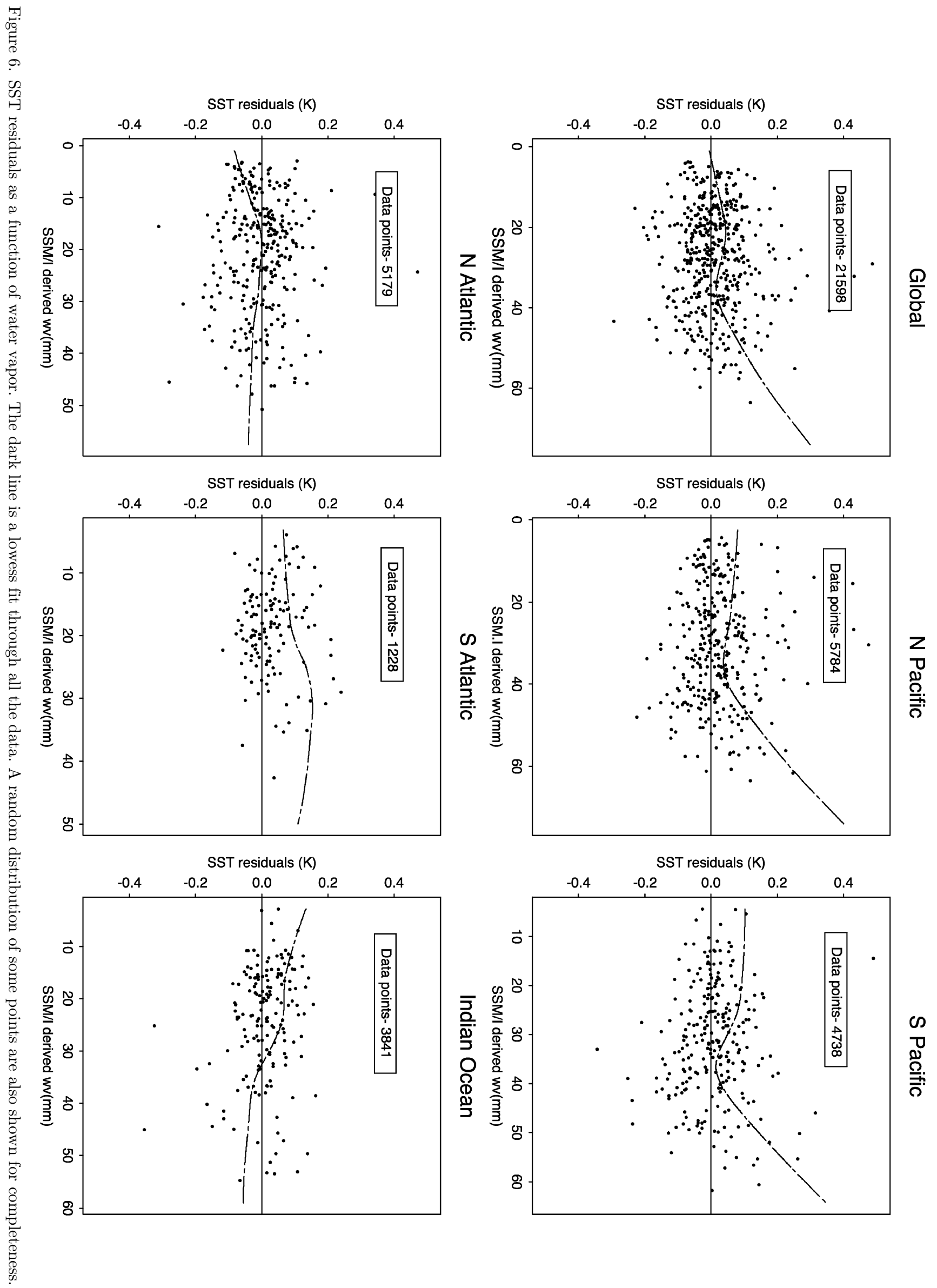


Indian Ocean and the S. Atlantic regions. The SST residuals also appear to show an inter-annual variation, especially in the Indian and Atlantic Oceans. These errors appear to increase generally during the summer months, when higher temperatures contribute to more water vapor in the atmosphere.

The performance of a global algorithm is better for the NOAA-14 partly due to better quality of matchups. By better quality we mean the satellite retrievals from new sensors, recovery from in situ buoys and better distribution of buoys to account for different atmospheres. The main problem arises in the difference between winter versus summer versus location of buoys that are later used in the regression coefficients. These differences can be reduced by improving on the "first" guess estimate of the SST in the algorithm, as suggested by Barton (1995). An improvement in the estimate of the absolute accuracy of the Pathfinder SST is found when satellite data are compared with the skin temperature measurements, rather than with measurements from buoys (Kearns et al 2000).

An interesting result in our analysis is that the channel difference appears to be unresponsive at high values of atmospheric water vapor. The change in the slope of T45 is consistent with more signal coming from the atmosphere as the atmospheric water vapor concentration increases. The decrease in SST residuals is attributed to the unresponsiveness of channel difference at water vapor values greater than $45 \mathrm{~mm}$ and zenith angles of $45^{\circ}$. It has been suggested that vertical distribution of water vapor in the atmosphere should be taken to account for the atmospheric absorption; in particular, the deviations from average profiles (Minnett 1987; Shenoi 1999). What still remains unanswered is why the satellite measurements in the N. Atlantic and the Caribbean regions have different error characteristics than elsewhere.

\section{Acknowledgements}

Ajoy Kumar is grateful to Dr. Satheesh C. Shenoi for all his suggestions, help and encouragement. This work was supported by the US National Aeronautics and Space Administration (NASA) through NAS56326, NAS5-31362 and NAG5-6577.

\section{References}

Barton I J 1995 Satellite-derived sea surface temperatures: Current status; J. Geophys. Res. 100 8777-8790

Brown J W, Brown O B and Evans R H 1993 Calibration of advanced very high resolution radiometer infrared channels: A new approach to nonlinear correction; J. Geophys. Res. 98 18257-18268

Emery W J, Yu Y, Wick G A, Schluessel P and Reynolds R W 1994 Correcting infrared satellite estimates of sea surface temperature for atmospheric water vapor attenuation; J. Geophys. Res. 99 5219-5236

Esaias W E, Abbott M R, Barton I, Brown O B, Campbell J W, Carder K L, Clark D K, Evans R H, Hoge F E, Gordon H R, Balch W M, Letelier R and Minnett P J 1998 An overview of MODIS capabilities for ocean science observations; IEEE, Transactions on Geoscience and Remote Sensing 36(4) 1250-1265

Eyre J R 1987 On systematic errors in satellite sounding products and their climatological mean values; $Q$. J. R. Meteorol. Soc. 113 279-292

Harries J E, Llewellyn-Jones D T, Minnett P J, Saunders R W and Zavody A M 1983 Observations of sea-surface temperature for climate research; Phil. Trans. R. Soc. London, A309 381-395

Kearns E J, Hanafin J A, Evans R H, Minnett P J and Brown O B 2000 An independent assessment of Pathfinder AVHRR sea surface temperature accuracy using the Marine-Atmosphere Emitted Radiance Interferometer (M-AERI); Bull. Am. Met. Soc. (In press.)

Kilpatrick K, Podestá G and Evans R 2001 Overview of the NOAA/NASA Pathfinder version 4.2 algorithm for sea surface temperature and associated matchup database (submitted to the Journal of Geophysical Research.)

Llewellyn-Jones D T, Minnett P J, Saunders R W and Zavody A M 1984 Satellite Multichannel infrared measurements of sea surface temperature of the N. E. Atlantic Ocean using AVHRR $/ 2$; Q. J. R. Meteorol. Soc. 110 613-631

Minnett P J 1986 A numerical study of the effects of anomalous North Atlantic atmospheric conditions on the infrared measurement of sea-surface temperature from space; J. Geophys. Res. 91 8509-8521

Minnett P J 1990 The regional optimization of infrared measurements of sea surface temperature from space; $J$. Geophys. Res. 95 13,497-13,510

Minnett P J 1995 Sea surface temperature measurements from the Along-Track Scanning Radiometer on ERS-1. In Oceanographic applications of remote sensing, (eds) M Ikeda and F Dobson (CRC Press Inc.) 131-143

Reynolds R W 1993 Impact of Mount Pinatubo aerosols on satellite-derived sea surface temperatures; J. Climate. 6(4) $768-774$

Reynolds R W and Smith T M 1994 Improved global sea surface temperature analysis using optimum interpolation; J. Clim. 7 929-948

Shenoi S C 1999 On the suitability of global algorithms for the retrieval of SST from the north Indian Ocean using NOAA/AVHRR data; Int. J. Remote Sensing 20 11-29

Strong A E and McClain E P 1984 Improved ocean surface temperatures from space-Comparisons with drifting buoys; Bull. Am. Meteorol. Soc. 85 138-142

Walton C C, Pichel W G, Sapper J F and May D A 1998 The development and operational application of nonlinear algorithms for the measurement of sea surface temperatures with the NOAA polar-orbiting environmental satellites; J. Geophys. Res. 103 27,999-28,012

Wentz F J 1989 User's manual, SSM/I geophysical tapes. RSS Technical Report 060989. Remote Sensing Systems. Santa Rosa, California. 16pp. (Available from NASA's JPL PODAAC)

Wick G A, Emery W J, Kantha L H and Schlussel P 1996 The behavior of the bulk-skin sea surface temperature difference under varying wind speed and heat flux; J. Phys. Oceanogr. 26 1969-1988

Zavody A M, Mutlow C T, Llewellyn-Jones D T 1995 A radiative transfer model for sea-surface temperature retrieval for the Along Track Scanning Radiometer; J. Geophys. Res. $100937-952$ 